\title{
International Debates and Reflections on the Successful Case of Montreal Protocol
}

\author{
Huiquan Chen ${ }^{1, \dagger}$, Tianlu Ding ${ }^{2, *},{ }^{*}$, Xinyue $\mathrm{Xu}^{3, \dagger}$ \\ ${ }^{1}$ College of Culture and Media, He Zhou University, Guangxi Province, China \\ ${ }^{2}$ Maxwell School of Citizenship and Public Affairs, Syracuse University, New York, US \\ ${ }^{3}$ Hefei No.8 high school, Anhui Province, China \\ *Corresponding author. Email: tding01@syr.edu \\ These authors contributed equally.
}

\begin{abstract}
The Montreal Protocol is widely considered one of the most successful multilateral environmental agreements, which succeeded in controlling the global emissions of ozone-depleting substances. This paper analyzes the efforts made by China on the London Amendment. The principle of 'common but differentiated responsibilities is discussed with China's own efforts on global ODS. Further analysis indicates that the Montreal Protocol has played an integral role in global warming in the current international environmental problems. Learning the case of Montreal and Kigali, this article summarizes the success of the amendment to protocols that can be attributed to the negotiations between developed and developing countries, which led to the establishment of the Multilateral Fund and a better understanding of the principle.
\end{abstract}

Keywords: Multilateral Fund, common but differentiated responsibilities, Kigali amendment, London Amendment.

\section{INTRODUCTION}

With several industrial revolutions ushered in the explosion of science and technology in human civilization in a short time, the development of human beings is getting faster and faster after entering modern times. Global warming, which is caused by modern industrial production, is getting more and more serious as well [1-3]. Under the influence of global warming, the glaciers on the earth are melting rapidly, and the sea level is rising inevitably, which shows that human beings cannot bear such natural consequences $[4,5]$. President Bush's administration was negative on reducing greenhouse gas emissions and refused to assign the Kyoto protocol and just to set up some long goal of protecting the environment. These actions lead to further pessimistic concerns. The exhaust gas produced by human activities that causes the rapid rise of the earth's temperature is the main reason for global warming. After the ozone layer hole is created, the ultraviolet radiation brought by the sun cannot be effectively blocked, and then the entire Earth's ecosystem will be destroyed. After the destruction of the ozone layer, the ability to absorb ultraviolet rays is greatly reduced, which will bring many effects on human health and the earth's organisms. For humans, the right amount of ultraviolet has a positive effect on the environment. Still, long-term exposure to excessive ultraviolet radiation will lead to intracellular DNA mutation, increasing the risk of serious diseases. For example, if the ozone layer in the stratosphere is reduced by $1 \%$, the number of cataracts on earth will increase by about $8 \%$, which will cause 10000 people to lose their sight. Excessive ultraviolet radiation will also increase the risk of skin cancer, measles, chickenpox, herpes, and other diseases [6,7]. In addition, excessive ultraviolet radiation has a great impact on aquatic organisms. Ultraviolet radiation can lead to the imperfect development of aquatic organisms and the decline of fecundity, which greatly impacts the marine biological chain, ecological balance, and water self-purification [810].

This article will deeply analyze the mechanism, conflict, and success factors of the protocol. It cannot be denied that the continuous reduction of the ozone layer will make the earth warm, pose a great threat to human society and natural ecology, and then have a great impact on the earth's economy. Fortunately, in 1987, a treaty that was universally ratified by all countries in the world, the Montreal Protocol, was signed. In addition, the Montreal Protocol is considered one of the most successful protocols to protect the environment [11]. Knowing 
deeply the consequences of the destruction of the ozone layer, countries around the globe united in the path of ozone layer repair. According to the U.S. Department of state, the Montreal Protocol aims to protect and repair the ozone layer by limiting and phasing out the production and consumption of ozone-depleting substances, also known as ODS. This Protocol focuses on phasing out the substances that are harmful to the ozone layer. The conference is set up once a year to make implement ensuring successful and effective. Protecting the ozone layer is beneficial for every country, and human beings are responsible for protecting their home. Accordingly, the Montreal protocol has no conflict on each country's advantage, which is one reason why it is successful. To understand how to achieve the agreement on the mutual advantages, this article will start its literature review from the financial system and then discuss the definition of differentiated responsibilities.

\section{THE FINANCIAL MECHANISM AND ITS DEBATES}

The creation of the financial mechanisms is one of the most valuable achievements in the Montreal Protocol. When the Protocol was promoted, its vague description of the aiming mechanism in Article 10 caused the rejection from many Article 5 countries, especially China and India [12]. As the protocol defines: "Article 5 countries are those developing countries whose annual calculated consumption of ozone-depleting substances is less than 0.3 kilograms per capita [13]." For those developing countries, the original version of Article 10 only proposed the concept of technical assistance, not the method, which they thought was unfair because of the unequal distribution as they were not the major producer and user of those ozone-depleting substances (ODS) [12]. As a consequence, a negotiation was held between developed countries and developing ones.

Before both sides reached an agreement, there was a conflict occurred. Firstly, those developing countries demanded that developed countries should pay for the future phase-out of ODS produced by Article 5 counties. In contrast, developed countries are worried about the idea that paying all the costs will cause endless commitment. Secondly, the structure of the voting system should be equally distributed among North and South, as developing countries demanded, it should not be fully advantageous to North's countries. Besides, they also indicated that the fund should be separated from the existing aid budget. By comparison, developed countries judged that all the finical transformation should be supervised under any donors or institutions such as the World Bank [12].

Fortunately, the Multilateral Fund (MLF), created during the London amendment in 1990, acknowledged the demand from developed and developing countries. It successfully satisfied the developing countries' equal voting and representing rights while maintaining the ultimate control rights of developed countries [14]. Its foundation reflects the achievement of the use of negotiation and diplomacy ability. As many scholars analyzed, the foundation of the Montreal Protocol could become a precedent for future global environmental issues and a standard for further international cooperation. Moreover, as an independent financial agency, its flexible and unique structure plays an important role in its foundation. First, based on Decision II/8 from Article 10 in the handbook of the Montreal Protocol [13], the MLF was managed by an Executive Commit-tee (ExCom), whose authority period was three years old. Within three-years, the remit of the ExCom should be regulated by and reporting any potential matters to the meeting of the parties. Besides, ExCom should cooperate with four institutions: the United Nations Environment Programme (UNEP), the United Nations Development Programme (UNDP), the International Bank for Reconstruction and Development (World Bank), and the United Nations Industrial Development Organization (UNIDO). Each of those agencies acts differently. UNEP's task is to act as an information center that supports Article 5 countries to exchange information and provide technology assistance. UNDP, on the other hand, worked with the World Bank, acting as the regulator of countries' projects. Specifically, while the World bank served mainly as the investor, the UNDP focuses on training technology and investment studies. Lastly, the UNIDO's primary task was to help the small-scale industrial comply with their obligations and offer cost-effective advice to support enterprises. As for today, 84 meetings have been held by the Executive Committee, and under the cooperation between different agencies, as of 2019, the MLF has received over US\$ 4.07 billion in total from non-article 5 countries and has also received the additional US \$25.5 million from donor countries to support the implementation of the HFC phase-down. However, although the MLF was largely admitted by countries and organizations, such question that whether ozone-depleting substances have indeed been reduced because of the establishment of the Multilateral Fund still remained questioned [15].

Fortunately, if we take into the specific statistics, these concerns should be eliminated. As the Article 5 countries in typical, China has benefited from the MLF and has achieved remarkable progress. As of 2010, about 800 million dollars from MLF have been allocated to more than 3000 enterprises. As for that time, China accounts for half of the total phase-out of ODS of all developed countries. Besides, under the MLF, many developing countries, article 5 countries, in particular, have successfully achieved the transfer of technology and strengthened their awareness of environmental protection [14]. Therefore, it is undeniably to conclude that the MLF is a win-win mechanism that helps article 5 countries meet the ODS requirement and served as a global 
agreement to raise international awareness towards the ozone-depleting issue.

However, the MLF was not the only financial mechanism adopted in the Montreal Protocol. The Global Environment Facility (GEF) has also played an important role. Unlike the MLF, although the GEF is not directly linked to the Montreal Protocol, it is positively supporting also helps many countries achieve their phaseout goal. In particular, according to the tenth meeting of the parties in the Montreal Protocol, the GEF's task is to focus on supporting countries with economies in transition (CEIT) since that CEIT was not counted as the Article 5 countries [7]. Specifically, the GEF has helped CEIT such as Russian Federation and nations in Eastern Europe and Central Asia to phase out their production and use of the chlorofluorocarbons (CFCs), halons, carbon tetrachloride (CTC), Hydro-chlorofluorocarbons (HCFCs), and methyl bromide. Besides the financial supports, the GEF also offered education and technology training in those countries. In the case of phrasing out the HCFCs, the GEF in 2008 has invested about $\$ 1,280,000.00$ for CEITs in Europe and Central Asia to support them in keeping up with their obligations and helping them to find an environmentally friendly technology [16]. There are many more projects held by the GEF. Undeniably, the implementation of the GEF filled the gap that actively supports that CEIT.

To sum up, although the MLF and the GEF are two independent financial systems, there is no comparability between them because they are responsible for different parts. However, there is one thing in common: they have supported many countries to accomplish their obligations. To date, many countries have 100 percent achieved the reduction of certain ODS. From the case of the MLF and the GEF, we should clearly acknowledge that success cannot be achieved simply by the financial fund, but with cooperation with partner governors and organizations and their long-term efforts to provide technology and education training. A key factor in the success of the Kigali Amendment was the US-China Economic Dialogue in 2013 and 2014, which led to a global agreement to phase down the production and consumption of HFCs domestically, bilaterally, and with other countries, driving the transition to climate-friendly refrigerants in the global refrigeration sector.

China is the world's largest exporter of HFCs, accounting for more than half of global exports. Using HFCs Products includes various types of air conditioning equipment and a wide range of refrigeration units and foam products. In 2018, thousands of enterprises engaged in the import and export of HFCs in China, with a total annual import and export volume of about 400,000 tons, which is nearly 10 times the number of ODS substances managed. In this regard, we have very significant responsibility and obligation to do a good job of HFCs control.
The National Development and Reform Commission, together with seven ministries and commissions of China, released the Green and Efficient Refrigeration Action Program specifically for the refrigeration and air conditioning industry in June 2019, indicating the importance that the government attaches to and puts into action the work of energy conservation and emission reduction in the refrigeration and air conditioning industry. The program requires that by 2022 , the market energy efficiency level of domestic household air conditioners and other refrigeration products will increase by $30 \%$, the market share of green and efficient refrigeration products will increase by more than $20 \%$, and annual electricity savings of about 100 billion $\mathrm{kWh}$ will be achieved. By 2030, refrigeration's overall energy efficiency level will be increased by another $25 \%$ or more [17]. If the amendment is fully implemented, it is expected that by about 2050, global emissions of HFCs will be reduced by $80 \%$ to $85 \%$, with a contribution to the prevention of global warming of up to $0.5^{\circ} \mathrm{C}$. According to the amendment, the reduction of HFCs in China could result in a climate benefit of 30 to 40 billion tons of $\mathrm{CO} 2$ equivalent emissions reduction by 2050 compared to the uncontrolled scenario, contributing to a one-third reduction in global warming of $0.5^{\circ} \mathrm{C}$ [17]. According to the reduction schedule, China will freeze its HFCs consumption below the baseline from 2024 and start phasing down from 2029 , achieving an $80 \%$ reduction in HFCs from the baseline level by 2045 .

\section{DISCUSSIONS ON SUCCESSFUL FACTORS}

When analysing the success factors, implementing the precautionary principle should be mentioned at the first stage. It utilizes the action of no-postponing, avoiding more serious and damaging consequences that would have resulted from the delay. Specifically, on the one hand, as early as 1975, the World Meteorological Organisation (WMO) and the United Nations Environment Programme (UNEP) became the "advance team" that advocating for the regulation of ozone depletion [18]. In the late 1970s, countries such as the United States and Canada were first to propose a ban on the use of Chlorofluorocarbons (CFCs) as a propellant in aerosol sprayers. Similarly, in 1985, a report of ozone depletion in the Antarctic elevated public concern and pressured the government to take action. All of this promoted the formation of an international scientific consensus that would be able to motivate more countries to promote the ban of CFCs [5]. However, although many scientists promoted the global plan on saving the ozone layer, the correlation between the health problem and the ozone depletion still remained uncertain. Fortunately, implementing the precautionary principle in the Montreal Protocol is from a political, not scientific, aspect. To be more clear, although the correlation still remained uncertain because science is full of variables, what 
governments need to do is take steps to stop further environmental degradation before it happens despite no accurate scientific results may be founded. Indeed, recent computer models indicate the negative consequences of not regulating the ozone-depleting substance (ODS) in the 1980s: our health will be affected, and the environment will deteriorate unpredictably. Therefore, it is undoubtedly to conclude that implementing the precautionary principle works well in the Montreal Protocol, and it will be continued works in the future.

Furthermore, the government and organizations had promoted many early actions that could be seen as the use of the precautionary principle. Among those actions, the Vienna Convention could be seen as a milestone. It gathered countries together to discuss the method of preventing the further deterioration of the ozone layer. Although the Vienna Convention did not provide specific and explicit obligations of ozone protection for each joined country, it gave the world an early warning that countries would join directly in the concrete implementation of the Montreal Protocol when the time was right.

The second success factor that scholars have analyzed is "the common but differentiated responsibilities." This can be divided into two parts. First, the common responsibilities mean countries and international organizations should share the same goals that reduce the emissions of the ODS, as well as raise the concept of ozone layer protection. This common responsibility significantly avoids the free-rider problem and is also effective against ozone depletion. Similarly, if a country stays out of the way, then it will certainly be blamed. Secondly, while the common responsibilities are important, one should not omit the differentiated responsibilities. Considering the high per capita emissions, historical responsibility, and level of economic of developed countries, they should prioritize emission reductions and provide technical and financial support to developing countries. These differentiated responsibilities allow developing countries to have a better balance between their fundamental development and achieving the goal of ozone protection and minimize the conflict of unequal emission targets.

More specifically, the conflict actually happened after the Montreal Protocol was first promoted. Several developing countries, including China and India, rejected the protocol because of the inequity. Fortunately, the second amendment, the London Amendment, revised the article and satisfied the demand of those developing countries. Unequivocally, the financial assistance, known as the Multilateral Fund (MLF), was designed for developing countries, which annual consumption levels are below $0.3 \mathrm{~kg}$ per capita, to support them in meeting their ODS phase-out requirement. In addition, international organizations and developed countries voluntarily donate money to developing countries to support their technology transition and give them more confidence to research on no ozone-depleting substances. Besides, the Global Environment Facility (GEF) provided financial assistance for those countries with economic transition, which did not meet the MLF requirement. For example, GEF implemented two objects for the former USSR (the Union of Soviet Socialist Republics) to help them meet the obligation of phrase out the ODS. In this case, the GEF filled the gaps and supported them to comply with the measures of the Protocol. Undeniably, the financial and technological assistance for developing countries and countries with economic transitions largely reduced the possibilities of non-compliance with the provisions of the Montreal Protocol and supporting them to break the technology barriers.

Next, the stable and flexible framework of the Montreal Protocol can also be counted as one of the factors of success. It is known to all that the Montreal Protocol was not strong enough to save the ozone hole and layer when it was first signed. However, with several amendments that have been promoted, the Montreal Protocol becomes even better. Among those amendments, the Kigali amendment makes the Montreal Protocol a more powerful tool against ozone depletion and global warming. More specifically, the Kigali amendment strengthens the Montreal Protocol by strengthening the control of HFCs as a complement to the Kyoto Protocol. As scholars analyzed, despite HFCs being the no ozone-depleting substances were used to replace $\mathrm{CFCs}$, studies show that HFCs are powerful greenhouse gases that will inevitably lead to global warming. Although the Kyoto Protocol aimed to control those alternative ODS that are actually greenhouse gases emissions, the Kigali Amendment emerged to further regulate the production and consumption of these gases, especially the hydro-fluorocarbons (HFCs). At the 28th meeting of the Montreal Protocol in 2016, more than 170 countries agreed to adopt the Kigali Amendment. In this way, the strong cooperation between the Kigali amendment and the Kyoto protocol maximized the environmental benefits and reduced cost. For all that, it is demonstrated the flexibility of the Montreal Protocol and shows the success of diplomatic cooperation and the ability of negotiation.

Meanwhile, one needs to raise citizens' awareness of ozone protection by joining IGO (Intergovernmental organization), NGO (Non-governmental organization), or commercial propaganda. In fact, on the road to protecting the ozone layer, NGOs served an important role in monitoring and promoting the implementation of the Montreal Protocol. According to Article 11.5 of the Montreal Protocol, NGOs can play a pressure role in the regulatory process. For example, many ozone-depleting substances are derived from everyday products. In this case, NGOs can rally consumers to put pressure on 
factories to reduce or eliminate the use of such substances.

\section{CONCLUSION}

This article has presented the most famous international environmental treaty on regulating substances that deplete the Ozone Layer-the Montreal Protocol-by revealing its unique mechanism, the ability to handle the challenge, and the reason for the success. As a well-known treaty, its determination to eliminating the ozone-depleting substances, the ability to solve the conflicts, and the efforts they did, such as the use of the precautionary principle and the foundation of the multilateral fund, to make the protocol even better was acknowledged to demonstrate an unprecedented ability to cooperate and negotiate internationally. All of these make for such a successful environmental treaty. Its works with the Kyoto Protocol marks the flexibility of diplomatic cooperation among related treaties. By the middle and end of this article, it is clear that the study of the Montreal Protocol is not limited to its achievements in the control of those ozone depletion substances, but rather, one needs to be acutely aware of the transnational cooperation, communication, and diplomatic strategies behind the protocol. Even though environmental protection remains a common topic for all mankind, and the climate problem continues to worsen despite the advocacy of the United Nations and other international organizations, the success of the Montreal Protocol has inspired many scientists and international organizations to take action against global warming. Although those actions seem not efficient, with the success of the Montreal Protocol as a foundation, scientists should be able to learn the unprecedented cooperation of international organizations and countries from the Montreal Protocol to model future developments. At the same time, people should not stop revising the Montreal protocol and researching new environmentally friendly technologies. Instead, one should be continuing to raise citizens' awareness of environmental protection by understanding the important role of ozone in the earth and the harmful consequences of not maintain the ecological balance because only in this way can people build a harmonious community of humans and nature.

\section{REFERENCES}

[1] Institute for Global Environmental Strategies. Environmental Governance and Electric Power Industry: - Global Warming -. Institute for Global Environmental Strategies, 1998, pp. 37-46, Business and Environmental Governance,

[2] Banning, Marlia E. "Exigency in Dispute: Global Warming and Uncertainty in Contemporary Rhetorical Criticism." JAC 31, no. 3/4 (2011): 63860 .
[3] McCright, Aaron M., and Riley E. Dunlap. "Challenging Global Warming as a Social Problem: An Analysis of the Conservative Movement's Counter-Claims." Social Problems 47, no. 4 (2000): 499-522.

[4] Abdullah, S. B. Ozone Layer Depletion and its Consequences on Humans: a Review. Environmental \& Analytical Toxicology, 2021.

[5] Kahraman, A., Kendon, E., Chan, S., \& Fowler, H. Quasi-Stationary Intense Rainstorms Spread Across Europe Under Climate Change. Geophysical Research Letters, 2008, 48(13).

[6] Larin, I. K. (2021). On the Influence of Global Warming on the Ozone Layer and UVB Radiation. Izvestiya, Atmospheric and Oceanic Physics, 57(1), 110-115.

[7] Urbach, Frederick. "Potential Health Effects of Climatic Change: Effects of Increased Ultraviolet Radiation on Man." Environmental Health Perspectives 96 (1991): 175-76.

[8] Robrecht, S., Vogel, B., Tilmes, S., \& Müller, R. (2021a). Potential of future stratospheric ozone loss in the mid-latitudes under global warming and sulfate geo-engineering. Atmospheric Chemistry and Physics, 21(4), 2427-2455.

[9] Mendelsohn, Robert, William D. Nordhaus, and Daigee Shaw. "The Impact of Global Warming on Agriculture: A Ricardian Analysis." The American Economic Review 84, no. 4 (1994): 753-71.

[10] Silu Bhochhibhoya, Michela Zanetti, Francesca Pierobon, Paola Gatto, Ramesh Kumar Maskey, and Raffaele Cavalli. "The Global Warming Potential of Building Materials: An Application of Life Cycle Analysis in Nepal." Mountain Research and Development 37, no. 1 (2017): 47-55.

[11] United States Environmental Protection Agency. International Treaties and Cooperation about the Protection of the Stratospheric Ozone Layer. EPA. Retrieved July 7, 2021, from https://www.epa.gov/ozone-layerprotection/international-treaties-and-cooperationabout-protection-stratospheric-ozone

[12] Zhao, J. (2005). Implementing International Environmental Treaties in Developing Countries: China's Compliance with the Montreal Protocol. Global Environmental Politics, 5(1), 58-81.

[13] UNIDO. The Montreal Protocol evolves to fight climate change | UNIDO. Retrieved July 8, 2021, from https://www.unido.org/our-focussafeguarding-environment-implementationmultilateral-environmental-agreements-montreal- 
protocol/montreal-protocol-evolves-fight-climate-

change

[14] Zhao, J. (2002). The Multilateral Fund and China's Compliance With the Montreal Protocol. The Journal of Environment \& Development, 11(4), 331-354.

[15] The Multilateral Fund. (n.d.). Welcome to the Multilateral Fund for the Implementation of the Montreal Protocol. The Multilateral Fund for the Implementation of the Montreal Protocol. http://www.multilateralfund.org/default.aspx

[16] Lauren, K. (2004). The Multilateral Fund for the implementation of the Montreal Protocol: addressing challenges of globalization - an independent evaluation of the World Bank's approach to global programs. Operations Evaluation Department (OED) Working Paper Series Washington, D.C. World Bank Group.

[17] Liu Wei. (2001). A glorious course: China's ten-year journey to protect the ozone layer. China Environment News.

[18] UNEP. Thirty years on, what is the Montreal Protocol doing to protect the ozone? https://www.unep.org/news-andstories/story/thirty-years-what-montreal-protocoldoing-protect-ozone 